\title{
Identification of the Inappropriate Clinical Actions (DON'T) to Improve the Management of Patients with Type 2 Diabetes Failing Basal Insulin Supported Oral Treatment: Results of Survey for a Panel of Diabetes Specialists in Italy
}

\author{
Gaetano Leto (D) - Ilaria Barchetta - Lorenzo De Candia • Maria Grazia Magotti • Marco Cianciullo • \\ Roberta Manti · Carlo Negri • Vincenzo Cimino • Alessandro R. Dodesini · Francesco Zerella • \\ Roberto Baratta
}

Received: May 31, 2021 / Accepted: August 2, 2021 / Published online: August 20, 2021

(c) The Author(s) 2021

\section{ABSTRACT}

Introduction: Despite the development of several recommendations, glycemic control in a large proportion of patients with type 2 diabetes, including those treated with insulin, remains suboptimal. This study is aimed to identify a set of actions to promote the reduction of inappropriate clinical practices in type 2

G. Leto $(\bowtie)$

Diabetology Unit, Sapienza University of Rome, Polo Pontino, Santa Maria Goretti Hospital, Latina, Italy

e-mail: gaetano.leto@uniroma1.it

I. Barchetta

Department of Experimental Medicine, Sapienza

University of Rome, Rome, Italy

L. De Candia

Diabetology Clinic, Hospital of Terlizzi, Bari, Italy

M. G. Magotti

Department of Intensive Treatment of Diabetes and its Complications, University Hospital of Parma,

Parma, Italy

M. Cianciullo

Department of Medicine, Nocera Inferiore Hospital, Salerno, Italy

R. Manti

Diabetology Unit, Santa Croce Hospital of

Moncalieri, Turin, Italy diabetes failing basal insulin supported oral therapy (BOT).

Methods: A panel of diabetes specialists was assembled to identify a list of ten corrective actions, "things not to do," for the management of type 2 diabetes: five concerning treatments, procedures and diagnostic tests and five about relationship, communication and information. The Choosing Wisely methodology and approach were the inspiration.

\section{Negri}

Department of Diabetology and Metabolic Diseases, Hospital of Verona, Verona, Italy

\section{Cimino}

Department of Biomedical and Clinical Sciences L. Sacco Endocrinology and Diabetology, Pio Albergo Trivulzio, Milan, Italy

A. R. Dodesini

Diabetology and Endocrine Diseases Unit, Papa

Giovanni XXIII Hospital, Bergamo, Italy

F. Zerella

Diabetology, Metabolic Diseases and Clinical

Nutrition, San Pio Rummo Hospital of Benevento, Benevento, Italy

R. Baratta

Endocrinology and Diabetology Unit, Department of Clinical and Experimental Medicine, University of Catania, Catania, Italy 
Results: A total of 73/73 (100\%) panelists responded to the survey. Twenty-four actions were proposed. The final list of inappropriate actions deemed most important to improve the management of patients with type 2 diabetes failing BOT were: (1) do not use secretagoguesdo not neglect the use of innovative glucoselowering agents; (2) do not underestimate the risk of lack of hypoglycemia awareness; (3) do not underestimate the benefit of personalization of therapy; (4) do not delay insulin intensification; (5) do not delay modification of the therapeutic regimen. In the area of patient communication, the following actions were identified: (1) do not fail to train in the management of hypoglycemia; (2) do not underestimate whether the patient has understood the modification of therapy; (3) do not prescribe injection therapy without adequately instructing the patient to titrate it; (4) do not ignore the patient's adherence; (5) do not stop listening to the patient and verify learning.

Conclusion: A set of corrective experiencebased actions to enact in a timely manner, which can assist physicians in improving clinical outcomes and patients' needs in terms of communications and interaction, is proposed. The list is intended to promote discussions among diabetes specialists to provide highvalue diabetes care.

Keywords: Type 2 diabetes; Basal insulin supported oral therapy; Treatment intensification; Patient communication

\section{Key Summary Points}

\section{Why carry out this study?}

Glycemic control in a large percentage of patients with type 2 diabetes, including those insulin-treated, remains inadequate.

An expert physician panel was assembled to identify ten corrective actions for the management of type 2 diabetes patients failing basal insulin-supported oral therapy taking inspiration from the Choosing Wisely methodology and approach.

\section{What was learned from the study?}

The panel discussion stressed the importance of using innovative glucoselowering agents based on an individual's needs and improved awareness of evidence-based treatments.

Panelists also highlighted the need to create more effective communication between the healthcare team and the patient.

\section{INTRODUCTION}

Type 2 diabetes (T2DM) is a chronic disease, with an increasing prevalence worldwide. By 2045, the International Diabetes Federation (IDF) predicts a $51 \%$ increase to approximately 700 million people diagnosed with diabetes [1]. Since the pathophysiology underlying the disease is characterized by progressive decreases in insulin secretion and sensitivity, therapy intensification with the use of insulin becomes necessary for many subjects.

Despite the development of several recommendations, glycemic control in a large proportion of patients with T2DM, including those treated with insulin, remains suboptimal in clinical practice, possibly due to therapeutic or clinical inertia. Both patient- and physician-related factors could represent barriers to the achievement of an optimal metabolic control. Calling attention to therapeutic inertia with appropriate strategies is a crucial step towards improving long-term outcomes [2].

Managing patients with long-standing T2DM is complex and necessitates careful consideration of clinical and patient factors representing a challenge for healthcare practitioners.

This study is the second phase of a project related to patients with T2DM failing basal insulin supported oral therapy (BOT) aimed to identify a set of actions to promote the reduction of inappropriate clinical practices [3].

There is, in fact, the emerging need to reduce or discontinue practices that are not supported 
by research evidence and real-life experience with the aim of providing high quality health care $[4,5]$.

Nonetheless, despite the development, the updating and the disclosure of specific consensus [6-8], their application in daily clinical practice is often lacking and the identification of any corrective actions would be important for improving diabetes care. Being inspired by the Choosing Wisely methodology and approach [9], a group of experts was assembled with the task of developing a list of ten corrective actions including five "things not to do" related to treatment, procedures and diagnostic test topics and five "things not to do" related to relationship, communication and information topics in the management of patients with T2DM in BOT failure.

\section{METHODS}

An 11-member group of experts (tutors) from different hospitals and settings (academic and public hospitals) on the national territory was selected based on their consolidated experience with diabetes (at least 10 years of clinical experience in diabetology) and being members of Italian scientific societies (Italian Diabetes Society, Association of Medical Diabetologists, Italian Society of Endocrinology, and Italian Society of Gerontology and Geriatrics) with the aim of identifying the practices at greatest risk of inappropriateness.

The initiative was born as a follow-up to a Consensus Delphi Project, the results of which have recently been published [3]. Six virtual meetings were organized, each of them moderated by two tutors. All 80 physicians who had taken part in the Delphi Survey were invited to attend the meetings. All the invitees had solid experience in the field of diabetes and were selected throughout the country from diabetes clinic medical staff, so that the whole country was homogeneously represented. Sixty-two of the 80 called upon joined and took part in the initiative on the theme of "management of type 2 diabetic patients failing basal insulin supported oral treatment." During each virtual meeting, the tutors presented and moderated the debate on the topics covered by the meeting. After the discussion, in a subsequent brainstorming session, participants were asked to identify a list of proposals for "actions to avoid" in the two areas of interest ("treatment, procedures, diagnostic tests" and "relationship, communication, information"), reflecting on what they observed and took place in their everyday clinical practice. In each of the six meetings approximately five cases were identified for each area of interest; subsequently, during a review phase, the list of proposed practices was modified to eliminate redundant and/or similar statements, thus yielding two lists of 24 "actions to avoid" for each area of interest (Tables 1 and 2).

The lists of 48 "actions to avoid" were uploaded online and administered to the group of 62 diabetes specialists (the panel) who had taken part in the virtual meetings to be voted on anonymously, expressing their personal opinion on the basis of the importance they attributed to each action to avoid. A consent statement was included on the introductory page of the online survey. Panel members were required to complete the declaration of consent before proceeding with the survey. The panel was then asked to rate each action/practice to be avoided on a five-point rating scale (Likert type) from $1=$ not at all important to $5=$ extremely important.

The characteristics and importance assessments voiced by the panelists were analyzed descriptively. A weighted score (WS) was calculated for each practice voted on.

\section{Compliance with Ethics Guidelines}

The study is based on a survey that does not contain any studies involving the participation of human subjects or patient data management and does not aim to modify the current clinical practice of participants. Consequently, according to current legislation (Legislative Decree 211/2003, a transposition of Directive 2001/20/ EU), this study did not require ethical approval. All experts involved in the survey were informed of the study's objectives and the possibility of publishing the results in a peer- 
Table 1 List of inappropriate practices in the therapy, diagnosis and procedures of patients with type 2 diabetes failing BOT

\begin{tabular}{lllllllll}
\hline Practice/procedure & 1 & 2 & 3 & 4 & 5 & $\begin{array}{l}\text { Weighted } \\
\text { score }\end{array}$
\end{tabular}

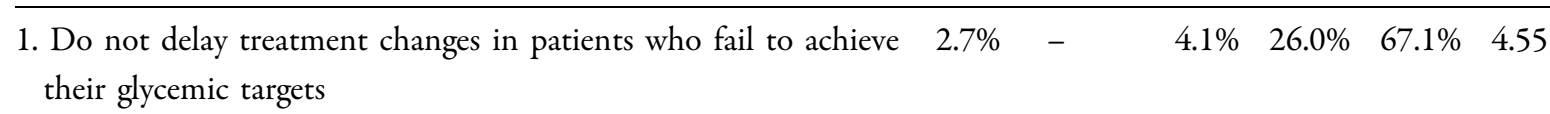

2. Do not start basal-bolus insulin therapy and keep it long term $\quad \begin{array}{llllll}4.1 \% & 2.7 \% & 12.3 \% & 34.2 \% & 46.6 \% & 4.16\end{array}$ without attempting alternative therapeutic strategies

3. Do not use sulfonylureas-glinides-Do not neglect the use of $\quad 4.1 \% \quad-\quad \quad \quad 2.7 \% \quad \begin{array}{lllll}17.8 \% & 75.3 \% & 4.60\end{array}$ SGLT2 inhibitors and/or GLP-1RAs in patients with high CV risk

4. Do not prescribe a sulfonylurea if no possible therapeutic alternative has been used

5. Do not underdose first-line metformin therapy

6. Do not ignore the use of GLP-1RAs in therapeutic strategies

7. Do not routinely determine the C-peptide in hospitalized patients

8. Do not prescribe C-peptide before starting insulin therapy

$12.3 \% \quad 26.0 \%$

$42.5 \%$

$13.7 \%$

$5.5 \% \quad 2.74$

9. Do not prescribe pancreatic enzymes before and during therapy

$11.0 \% \quad 26.0 \%$

$32.9 \%$

$21.9 \%$

$8.2 \% \quad 2.90$ with GLP-1RAs and DPP-4 inhibitors

10. Do not leave SU when starting insulin therapy

11. Do not discontinue metformin treatment with basal-bolus (unless there is a problem with glomerular filtrate)

12. Do not start the insulin before the GLP-1RAs

13. Do not underestimate the risk of lack of hypoglycemia awareness

14. Do not prescribe metformin without first assessing the eGFR and/or the risk of acute renal failure

15. Do not delay the intensification of diabetes therapy

$\begin{array}{llllll}4.1 \% & 6.8 \% & 13.7 \% & 19.2 \% & 56.2 \% & 4.16\end{array}$

$\begin{array}{llllll}4.1 \% & 4.1 \% & 30.1 \% & 37.0 \% & 24.7 \% & 3.74\end{array}$

16. Do not underestimate the benefit of personalization of therapy in relation to the patient's comorbidities (i.e., $\mathrm{CV}$ risk factors)

17. Do not forget to stratify the patient's CV risk

$2.7 \% \quad-\quad \begin{array}{lllll}6.8 \% & 34.2 \% & 56.2 \% & 4.41\end{array}$

18. Do not consider the cost of therapy rather than the cost of the

$\begin{array}{llllll}11.0 \% & 15.1 \% & 23.3 \% & 20.5 \% & 30.1 \% & 3.44\end{array}$ disease

19. Do not consider exclusively the 'glycaemia' endpoint in the

$5.5 \% \quad 1.4 \%$

$6.8 \%$

$17.8 \%$

$68.5 \% \quad 4.42$ management of the disease, neglecting cardiovascular and renal protection 
Table 1 continued

\begin{tabular}{|c|c|c|c|c|c|c|}
\hline Practice/procedure & 1 & 2 & 3 & 4 & 5 & $\begin{array}{l}\text { Weighted } \\
\text { score }\end{array}$ \\
\hline $\begin{array}{l}\text { 20. Do not leave out the PK and PD characteristics of the drug to } \\
\text { limit glycemic variability }\end{array}$ & $2.7 \%$ & $6.8 \%$ & $27.4 \%$ & $39.7 \%$ & $23.3 \%$ & 3.74 \\
\hline $\begin{array}{l}\text { 21. Do not use the "sliding scale" insulin scheme by modifying the } \\
\text { insulin dosage on the basis of pre-meal or bed-time blood sugar } \\
\text { levels }\end{array}$ & $6.8 \%$ & $8.2 \%$ & $26.0 \%$ & $27.4 \%$ & $31.5 \%$ & 3.68 \\
\hline $\begin{array}{l}\text { 22. Do not continue oral hypoglycemic therapy at home in acute } \\
\text { patients in hospital }\end{array}$ & $2.7 \%$ & $2.7 \%$ & $19.2 \%$ & $26.0 \%$ & $49.3 \%$ & 4.16 \\
\hline $\begin{array}{l}\text { 23. Do not administer insulin by syringe. both in the hospital and at } \\
\text { home }\end{array}$ & $6.8 \%$ & $8.2 \%$ & $17.8 \%$ & $23.3 \%$ & $43.8 \%$ & 3.89 \\
\hline $\begin{array}{l}\text { 24. Do not underestimate the importance of adequate titration of } \\
\text { insulin or combinations with basal insulin }\end{array}$ & $2.7 \%$ & $4.1 \%$ & $2.7 \%$ & $26.0 \%$ & $64.4 \%$ & 4.45 \\
\hline
\end{tabular}

reviewed article. The participation was voluntary. They expressed their consent to participate in the survey after logging into the secure online survey platform via credentials, by actively clicking on the appropriate box.

\section{RESULTS}

A total of 73 diabetologists $(100 \%$ of those contacted) participated in the survey. According to the weighted score reached by each action, five practices to avoid for each area were identified.

The WSs for the area related to treatment, procedures and diagnostic tests was highest for the following practices:

- Do not use sulfonylureas-glinides; do not neglect the use of sodium-glucose co-transporter-2 (SGLT2) inhibitors and/or glucagonlike peptide- 1 receptor agonists (GLP-1RAs) in patients with high cardiovascular (CV) risk (WS $=4.60$ ).

- Do not underestimate the risk of lack of hypoglycemia awareness (WS $=4.58$ ).

- Do not underestimate the personalization of therapy in relation to the patient's comorbidities (e.g., CV risk factors) (WS $=4.56$ ).
- Do not delay the intensification of diabetes therapy (WS $=4.56$ ).

- Do not dekay treatment changes in patients who fail to achieve their glycemic targets (WS $=4.55)$.

The five practices to avoid selected according to the highest WS for the area related to relationship, communication and information were the following:

- Do not fail to train the patient in the management of hypoglycemia when prescribing hypoglycemic therapy (WS $=4.68$ ).

- Do not assume that the patient has understood the modification of the prescribed therapy (WS $=4.60$ ).

- Do not prescribe injection therapy without adequately instructing the patient to titrate it $(\mathrm{WS}=4.53)$.

- Do not ignore the patient's adherence to therapy, lifestyle and social status (WS = 4.52).

- Do not stop listening to the patient and verify learning (WS $=4.49$ ). 
Table 2 List of inappropriate practices in the relationship with, communication with and informing of patients with type 2 diabetes failing BOT

\begin{tabular}{lllllllll}
\hline Practice/procedure & 1 & 2 & 3 & 4 & 5 & $\begin{array}{l}\text { Weighted } \\
\text { score }\end{array}$ \\
\hline
\end{tabular}

1. Do not ignore the patient's adherence to therapy, lifestyle and social $\quad 2.7 \% \quad 2.7 \% \quad-\quad 28.8 \% \quad 65.8 \% \quad 4.52$ status

2. Do not exclude/neglect the caregiver or cultural mediator regarding $\quad 2.7 \% \quad 2.7 \% \quad 15.1 \% \quad 37.0 \% \quad 42.5 \% \quad 4.14$ therapeutic indications

3. Do not minimize patient-reported drug side effects

$\begin{array}{llllll}1.4 \% & 2.7 \% & 13.7 \% & 43.8 \% & 38.4 \% & 4.15\end{array}$

4. Do not associate injection therapy with disease severity

$\begin{array}{llllll}1.4 \% & 5.5 \% & 28.8 \% & 35.6 \% & 28.8 \% & 3.85\end{array}$

5. Do not forget at each visit to check the current therapy,

$\begin{array}{llllll}2.7 \% & 2.7 \% & 4.1 \% & 24.7 \% & 65.8 \% & 4.48\end{array}$ pharmacological or not, and the therapeutic simplification

6. Do not neglect the relationship of injection therapy, poor metabolic compensation and lipodystrophy

7. Do not underestimate knowing whether the patient has understood the modification of the prescribed therapy

8. Do not neglect the therapeutic objectives that the patients are willing to pursue by making them a participant in the treatment proposal

9. Do not underestimate the control of remaining cardiovascular risk factors (LDL, BP), particularly at the time of prescribing the secondline therapy and in women with diabetes

10. Do not use non-comprehensible scientific terms

11. Do not prescribe a drug without sharing the choice with the

$\begin{array}{llllll}1.4 \% & 2.7 \% & 13.7 \% & 39.7 \% & 42.5 \% & 4.19\end{array}$ patient and without instructing him/her in a complete and correct way

12. Do not prescribe injectable medication without adequately instructing the patient to titrate it

13. Do not stop listening to the patient and verifying learning
$4.1 \% \quad-\quad 2.7 \% \quad 28.8 \% \quad 64.4 \% \quad 4.49$
$\begin{array}{lll}1.4 \% & 2.7 \% \quad 6.8 \%\end{array}$
$24.7 \%$
$64.4 \%$
4.48

14. Do not forget about educational therapy (diet, lifestyle counseling, etc.)

15. Do not neglect to inform about the potential side effects of drugs

$1.4 \% \quad 2.7 \% \quad 9.6 \%$

$42.5 \% \quad 43.8 \% \quad 4.25$

16. Do not give long-term appointments for patients who change

$2.7 \%$

$6.8 \%$

$11.0 \%$

$41.1 \% \quad 38.4 \% \quad 4.05$ therapy

17. Do not fail to involve GPs in the treatment process

$\begin{array}{llllll}2.7 \% & 5.5 \% & 21.9 \% & 30.1 \% & 39.7 \% & 3.99\end{array}$

18. Do not say "you must" and "its your fault"

$2.7 \% \quad 2.7 \% \quad 9.6 \%$

$39.7 \% \quad 45.2 \% \quad 4.22$

19. Do not forget to listen to the patient actively or neglect non-verbal

$1.4 \% \quad 4.1 \% \quad 6.8 \%$

$41.1 \% \quad 46.6 \%$

4.27 communication to build a solid therapeutic relationship 
Table 2 continued

\begin{tabular}{|c|c|c|c|c|c|c|}
\hline Practice/procedure & 1 & 2 & 3 & 4 & 5 & $\begin{array}{l}\text { Weighted } \\
\text { score }\end{array}$ \\
\hline 20. Do not fail to educate the patient about insulin titration & $4.1 \%$ & $2.7 \%$ & $5.5 \%$ & $17.8 \%$ & $69.9 \%$ & 4.47 \\
\hline $\begin{array}{l}\text { 21. Do not fail to train the patient in the management of } \\
\text { hypoglycemia when prescribing hypoglycemic therapy }\end{array}$ & $1.4 \%$ & $1.4 \%$ & $4.1 \%$ & $13.7 \%$ & $79.5 \%$ & 4.68 \\
\hline 22. Do not have an unstructured self-check of blood glucose & $2.7 \%$ & $2.7 \%$ & $13.7 \%$ & $35.6 \%$ & $45.2 \%$ & 4.18 \\
\hline 23. Do not fail to train the patient to manage therapy on sick days & $2.7 \%$ & - & $9.6 \%$ & $34.2 \%$ & $53.4 \%$ & 4.36 \\
\hline 24. Do not assume that the patient has a diet & $1.4 \%$ & $4.1 \%$ & $15.1 \%$ & $31.5 \%$ & $47.9 \%$ & 4.21 \\
\hline
\end{tabular}

\section{DISCUSSION}

\section{Area "Treatment, Procedures and Diagnostic Tests"}

\section{Do Not Use Sulfonylureas-Glinides-Do Not Neglect the Use of SGLT2 Inhibitors and/ or GLP-1RAs in Patients with High Cardiovascular Risk}

Among the actions to avoid in the management of patients with T2DM, a main important theme that emerged was the recommendation to avoid secretagogues, preferring innovative therapeutic strategies with SGLT2 inhibitors and GLP-1RAs in patients with high CV risk. These innovative classes of glucose-lowering agents demonstrated CV benefits in Cardiovascular Outcomes Trials, bringing in a new era in the management of T2DM.

Although the most recent consensuses recommend SGLT2 inhibitors and/or GLP-1RAs in the management of patients with ascertained $\mathrm{CV}$ disease or at very high CV risk [6-8], sulfonylureas are still widely used as an add-on treatment.

A recent study from electronic medical records of patients treated at Italian diabetes centers documented a considerable use of secretagogues and glinides also in the classes with higher CV risk (16.3\%) [10]. Furthermore, sulfonylureas still represent a frequently adopted therapeutic strategy associated with basal insulin, also in the DARWIN T2D study [11]. A large descriptive study on American ambulatory care physicians documented a slight decline in second-line sulfonylurea and a concomitant important increase in SGLT2 inhibitor use [12].

On the other hand, in clinical practice, the percentage of patients receiving GLP-1RA treatment remained low, ranging between 2.4 and $6.4 \%$ in moderate, high and very high $\mathrm{CV}$ type 2 diabetic populations. The percentage of patients receiving SGLT2 inhibitors was slightly higher ranging from 8.5 and $10 \%$ in the same categories [10].

Although sulfonylureas have high glucoselowering efficacy and low cost, their use raises concerns since they are associated with weight gain, risk for hypoglycemia and a lack of durable effect on glucose lowering [6]. Finally, the use of sulfonylureas has recently been associated with an increased risk of all-cause mortality, while no significant increased risk of major CV events was observed [13].

Strong evidence showed that SGLT2 inhibitors and/or GLP-1RAs are associated with low hypoglycemia risk, promote weight loss and exert a positive impact on vascular, cardiac and renal endpoints. Thus, the use of sulfonylureas instead of SGLT2 inhibitors or GLP-1RAs may deprive patients of advantages and potentially important CV and renal benefits. Routine utilization of sulfonylureas as second-line agents continues to be acceptable in resource-constrained settings [14].

To this end, the panel agreed that innovative glucose-lowering agents such as GLP-1RAs or SGLT2 inhibitors should be preferred to secretagogues in high CV risk patients. 


\section{Do Not Underestimate the Risk of Lack of Hypoglycemia Awareness}

People with T2DM on insulin treatment are at risk for hypoglycemia, which can negatively impact physical and emotional well-being [15]. Several real-world studies showed a prevalence of $4-17 \%$ insulin-treated patients reporting severe hypoglycemia needing assistance and $37-64 \%$ experiencing any hypoglycemic symptoms over a 12-month period [16]. However, although $88-98 \%$ of all hypoglycemic episodes can be classified as non-severe hypoglycemic events, they have been shown to affect functioning, quality of life, healthcare resource use and work productivity [17].

Less is known regarding lack of hypoglycemia awareness in T2DM. Real-world surveys of insulin-treated patients with T2DM showed that 6-19\% lacked hypoglycemia awareness [17-19] and the incidence of severe hypoglycemia was 17 -fold higher than in those with normal hypoglycemia awareness [19].

The underlying cause of lack of hypoglycemia awareness should be sought in recurrent episodes of asymptomatic, non-severe hypoglycemia, which can induce a process of habituation leading to impaired awareness of hypoglycemia. The process can be reversed by strict avoidance of hypoglycemia [20].

A large retrospective Italian study found that $26.4 \%$ of insulin-treated patients tested their blood glucose (self-monitoring blood glucose [SMBG]) less than once a day, and the incidence of hypoglycemia was higher in patients not using SMBG compared to those with daily use [21]. In this respect, the continuous glucose monitoring (CGM) system can be a useful tool to detect unwarranted onset of hypoglycemic events. An observational study on T2DM showed, in fact, that hypoglycemia detected by CGM was frequently unrecognized by the patients (75\%) [22].

To this end, the panel underscored a need to consider lack of hypoglycemia awareness as a topic issue in the management of patients undergoing BOT therapy. Use of a tailored approach, associated with patient stratification, can help individualize patients at risk of lack of hypoglycemia awareness who can benefit from the use of CGM and the prescription of newer glucose-lowering drugs with low risk of hypoglycemic events.

\section{Do Not Underestimate the Personalization of Therapy Related the Patient's Comorbidities} (i.e., CV Risk Factors)

Given the large spectrum of possibilities of glucose-lowering agents with differences in mechanism of action, tolerability profile, costs and indications, diabetes management should be an individualized approach tailored to each patient's clinical profile including frailty and comorbid conditions.

$\mathrm{CV}$ complications still represent the main cause of mortality in patients with T2DM [23]. Clinical recommendations emphasize the importance of carefully assessing the patient's $\mathrm{CV}$ risk profile at a very early stage of the disease to identify the best possible therapeutic strategy.

The choice of a glucose-lowering agent is no longer related exclusively to the effectiveness in terms of hypoglycemic effect but should also be based on the extra glycemic properties of the different agents. The use of GLP-1RAs, in fact, is recommended in patients at high risk for or established atherosclerotic CV disease (ASCVD); SGLT2 inhibitors, on the other hand, are recommended in patients with heart failure, with and without coronary artery disease, also to prevent the progression of chronic kidney disease [7]. Furthermore, the US Food and Drug Administration (FDA) has recently approved dapagliflozin to reduce the risk of kidney function decline, kidney failure, CV death and hospitalization for heart failure in adults with chronic kidney disease at risk of disease progression, regardless of the presence or absence of diabetes [24].

The updated ESC/EASD consensus classified patients with T2DM in different CV risk classes considering patients with established CV disease, target organ damage or multiple major risk factors as a very high-risk category and patients with diabetes duration $\geq 10$ years and additional risk factors as high risk [8]. These recommendations were even more incisive for indicating GLP-1RAs or SGLT2 inhibitors in drug-naïve patients with established ASCVD or those at high or very high risk (diabetes 
duration $\geq 10$ years without target organ damage plus any other additional risk factors) [8].

A recent Italian study based on real-world data demonstrated that, although most individuals with T2DM could be classified as very high CV risk (78.5\%) or high CV risk (20.9\%), the classes of glucose-lowering agents with proven CV benefits, particularly GLP1-RAs and SGLT2 inhibitors, were underused [10]. Other evidence comes from an American study that observed only a small portion of eligible patients with myocardial infarction, heart failure, kidney disease and prior hypoglycemia, treated with cardio-protective agents such as SGLT2 inhibitors, probably because of cost and clinical inertia [25].

Other factors affect the choice of glucoselowering agents, particularly in the setting of patient-centered care such as weight, hypoglycemic risk, treatment cost and other patientrelated factors that may influence treatment selection [6].

The panel emphasized the need to develop a personalized treatment plan for each patient, which maximizes the benefits of therapy, reducing or maintaining the blood glucose to nearly normal levels while minimizing adverse effects to ensure optimal treatment outcomes.

\section{Do Not Delay Intensification of Diabetes Therapy}

Due to the progressive nature of diabetes disease, many patients with T2DM treated with insulin do not achieve their glycemic targets [26], and intensification of insulin therapy becomes of crucial importance. ADA guidelines emphasize the importance of timely treatment intensification recommending additional therapy when the hemoglobin A1c (HbA1c) target is not achieved after 3 months [27]. In fact, early treatment intensification increases the likelihood of subsequent glycemic control [28].

Patients often remain above target for several years before treatment intensification. A retrospective cohort study revealed that a 1-year delay in treatment intensification in patients with inadequate metabolic control significantly increased the risk of myocardial infarction $(67 \%)$, stroke $(51 \%)$, heart failure $(64 \%)$ and composite macrovascular events (62\%) [29].
The median time until intensification in insulin-treated patients was 3.7 years from starting basal insulin, despite having an $\mathrm{HbA} 1 \mathrm{c}>7.5 \%(58 \mathrm{mmol} / \mathrm{mol})$. This delay in treatment intensification was associated with older people and longer diabetes duration [30].

One of the key reasons is therapeutic inertia, which is the failure to initiate or intensify therapy promptly. It is related to several factors, including lack of time, poor training and lack of familiarity with the recognition and management of side effects of new therapeutic options. In addition, the fear of increased risk of hypoglycemia, weight gain and difficulty in managing more complex strategies can also be mentioned [31, 32].

Current consensuses recommend intensifying basal insulin treatment with GLP-1RAs or SGLT2 inhibitors rather than prandial insulin [6]. The combination of basal insulin with these therapeutic options permits addressing the unmet medical needs due to the complementary mechanisms of action to target multiple aspects of disease pathophysiology with a low rate of hypoglycemia and weight loss. CV safety in terms of major CV event risk reduction is well established for the monocomponents [33-35].

Furthermore, fixed-ratio combinations of basal insulin and GLP-1RAs may be considered useful therapeutic options to prescribe because of the advantage of a less complex treatment regimen, with only a single daily injection. The two available fixed-ratio combinations, iGlarLixi (a combination of insulin glargine and lixisenatide) and IDegLira (a combination of insulin degludec and liraglutide), both demonstrated greater glycemic control compared with their individual components alone, while demonstrating good safety and tolerability profiles [36, 37].

In light of these considerations, panelists consider delaying the intensification of therapy as an inappropriate practice in the management of patients in BOT failure.

\section{Do Not Delay Treatment Changes in Patients Who Fail to Achieve Their Glycemic Targets} Available guidelines stress the importance of optimal glycemic control as the cornerstone of diabetes management [6-8]. Despite these 
recommendations, glycemic control remains suboptimal in a high proportion of patients with T2DM, including those who have started insulin treatment. Italian observational data indicated that 2 years after starting insulin therapy, HbA1c levels were still $>8 \%$ in almost $50 \%$ of patients surveyed [38].

In addition to insulin intensification, another approach to overcome therapeutic inertia is the modification of basal insulin. The newer longer-acting basal insulin analogs (insulin glargine $300 \mathrm{U} / \mathrm{ml}$ and degludec), which closely resemble endogenous insulin secretion patterns, demonstrated lower variation in glucose-lowering effect (throughout the day and from day to day) associated with a low risk of hypoglycemia. These effects were evident also in older adults and in individuals with obesity, renal impairment, a history of $\mathrm{CV}$ disease or a long duration of insulin use. These effects resulted in a greater flexibility in the timing of injection and a consequent facilitation of glycemic management [39].

Improvements in clinical outcomes were demonstrated in interventional studies, irrespective of previous basal insulin therapy $[40,41]$. The data were confirmed in a European real-world study, which evaluated the clinical effectiveness of switching to degludec in insulin-treated subjects with diabetes under routine clinical conditions; the study showed an improvement of glycemic control and a significant decrease in the risk of hypoglycemia with lower or similar insulin dose requirements in patients switching to degludec from other basal insulins [42].

For these reasons, the expert panel concluded the need not to delay therapeutic modification in patients with inadequate metabolic control.

\section{Area "Relationship, Communication, Information"}

\section{Do Not Fail to Train the Patient in the Management of Hypoglycemia When Prescribing Hypoglycemic Therapy}

In insulin-treated patients, fear of hypoglycemia could become an obstacle to achieving optimal metabolic control because it can bring toward an under-dosing of insulin. Furthermore, hypoglycemia was found to have an impact also on medication discontinuation: a study based on a claims database found that the risk for medication discontinuation was significantly higher among patients experiencing a hypoglycemic event vs. those with no reported hypoglycemia [43].

All strategies to prevent, monitor and treat hypoglycemic events for better awareness of hypoglycemia should be applied. To achieve these aims, it is essential to implement a collaboration between healthcare professionals and people with diabetes. A dialogue with patients about the risks of hypoglycemia is critical to prepare them to recognize the signs and symptoms and the appropriate treatment. During each visit physicians should inquire about all types of hypoglycemic episodes that have occurred, addressing issues related to symptoms and glucose testing and encouraging patients to record and report their experiences during hypoglycemic events and related glucose levels. Glucose targets, testing schedule and treatment plan should be reviewed often and individualized to minimize the risk of hypoglycemia [44].

A large survey on self-reported frequency of non-severe hypoglycemic events in real-world practice in the seven countries in Europe found that only half of patients with T2DM (50-59\%) rarely or never informed their general practitioner/specialist about their hypoglycemic events. Despite these results, only $21-28 \%$ of respondents reported that their physician did not ask them about hypoglycemia during routine visits, suggesting some level of communication regarding hypoglycemic events is taking place [17].

Several experiences demonstrated that structured interventions that included patient education could significantly reduce the frequency of severe hypoglycemia in T2DM [45].

To this end, the panel advocates the education and training of people with diabetes in timely and appropriate treatment of hypoglycemia. 


\section{Do Not Assume that the Patient Has Understood the Modification of the Prescribed Therapy}

Many patients tend to be skeptical about prescribed medications, especially if they are a new-generation agent, often fearing that the long-term risks outweigh the benefits [46]. These worries about the potential negative impact of medications could be associated with low adherence and reluctance to modify their therapy initiating new drugs [47].

Patients are more likely to be adherent to therapy when they perceive that the prescribed medication is actually necessary and will contribute to a positive outcome [48]; on the other hand, discouraged patients may discontinue their treatment. To this end, patients' beliefs about effectiveness and risk of the medications are an important factor to consider when trying to understand the reasons for non-adherence [49].

Specific instructions, individualized according to patients' lifestyle and social status, are fundamental to obtaining a proactive approach with patients to achieve acceptance of the new therapeutic strategy and the evaluation of the progress achieved [49].

The panel underscored a need to dedicate time to communicating the modification of prescribed therapy to the patient, making sure that he or she really understands this modification. Such beliefs are likely to need to be reinforced if patients do not see improvements in glucose levels.

\section{Do Not Prescribe Injectable Medications Without Adequately Instructing the Patient to Titrate It}

In strategies involving injectable medications, titration is a key element of the therapeutic regimen required by individuals with T2DM to achieve adequate metabolic control.

Titration of insulin or non-insulin injectable medications can be performed by either the patient or their healthcare team, according to the patient's ability, willingness and motivation. If delayed, titration inertia could lead to therapeutic failure. Studies indicated that once treatment with basal insulin had been initiated, glycemic control was still not achieved in most cases and that this was partly attributable to insufficient titration of insulin [31].

Lack of flexibility and complex titration algorithms constitute a major cause for concern in individuals with diabetes. These factors are often accompanied by lack of adequate healthcare resources and practitioners and inadequate educational programs for effective titration [2].

A survey conducted in the USA, France and Germany involving both patients with T2DM and physicians highlighted that although physicians recognized the importance of discussing insulin titration with patients, and the majority reported doing so, only a minority of patients remembered this type of information. These findings suggest that communication between physicians and patients should be improved and key messages regarding titration should be strengthened at each visit to obtain patient confidence in diabetes management [50].

Simplified, safe and effective titration algorithms which can be tailored and individualized should be considered [49].

The panel considers prescription of injectable medications without appropriate instruction on the titration algorithm a poor solution that risks leading to therapeutic failure.

\section{Do Not Ignore the Patient's Adherence to Therapy, Lifestyle and Social Status} Individuals with T2DM are progressively treated with multiple-medication regimens, including oral and injectable medications. Medication regimen complexity has been identified as one of the significant contributors to the prevalence of non-adherence; consequently, interventions aimed to reduce regimen complexity are sought to have a potential impact on the level of medication adherence [43, 51, 52]. Adherence rates for patients with chronic diseases, including T2DM, were found to be significantly associated with number of doses per day; in particular, medication adherence was lower for any medication regimen requiring more than once-daily dosing [46].

Non-adherence to prescribed medications was more prevalent among patients on longterm therapeutic plans and was associated with 
an increased risk of hospitalization and mortality risks [53].

The use of a fixed-dose combination is one of the strategies that could be applied for medication regimen simplification. This strategy can also be considered an approach to initiate, modify and individualize therapeutic regimes to further encourage patient compliance [54].

Socioeconomic factors and lifestyle should also be considered in an overall diabetes management: work schedules (e.g., shift work) that can alter sleep patterns, mealtimes and injection times should be discussed and considered. Furthermore, social determinants of health (defined as the circumstances in which people are born, live and work) significantly impact outcomes for patients with diabetes. Awareness of the presence of these determinants can enhance the development of culturally customized programs. Healthcare professionals should be experienced in assessing the social determinants of health and considering them in clinical care [55].

Therefore, the panel emphasized the need for physicians to adequately consider patient's adherence to therapy, lifestyle and social status to avoid therapeutic failure.

\section{Do Not Stop Listening to the Patient and Verify Learning}

Physician-patient communication, including patient understanding, trust and doctor-patient agreement on disease management, can affect health outcomes. The immediate results could be observed as intermediate outcomes (e.g., better adherence), which, in turn, affect patient health outcomes and well-being [56]. In fact, it has been shown that the more patients know and understand about their condition and insulin treatment, the greater their chance for success. This may include an appointment with a diabetes educator or nutritionist when available [49]. It is also important to assess how much the patient understands and provide access to education when needed and how patient recall of information can be increased by improving effective communication. In this context, it is important to verify the effectiveness of reinforcing education on correct injection technique (injection site rotation, insulin pen use) to avoid local complications such as lipodystrophy in insulin-treated subjects. This is one of the most common complications about subcutaneous insulin therapy and may present as either lipoatrophy or lipohypertrophy at the insulin injection sites. An inadequate injection technique is usually considered the main risk factor for lipodystrophies, which may cause inexplicable glycemic oscillations and hyper- or hypoglycemic episodes [57-60].

The panel of experts, therefore, recommends maintaining good communication with the patient to verify that all the instructions provided have been properly received.

There are some limitations to the study. There is no guarantee that the results of the survey are generalizable; results are dependent on the limited number and the composition of the respondents. However, to minimize the potential for selection bias, panelists were selected based on their experience in the field of diabetes and their distribution throughout all regions of Italy. Furthermore, some important issues, such as the correct insulin injection technique in a population with T2DM failing BOT, have not been fully investigated.

\section{CONCLUSIONS}

In conclusion, some of the aspects of diabetes management in patients with T2DM in basal insulin-supported oral treatment remain inadequate. Therefore, a set of corrective experiencebased actions, to enact in a timely manner, to assist physicians in improving clinical outcomes and patients' needs in terms of communications and interaction is proposed.

There is, in fact, a potential to increase the efficacy of therapeutic regimens by optimizing intensification strategies and therapeutic modifications and by exploring specific patient groups who will particularly benefit from innovative hypoglycemic agents, especially in patients with high CV risk.

Treatment of T2DM should be selected based on an individual's needs, guideline recommendations, most advanced knowledge and the course of diabetes progression. Consideration must also be given to constructing improved 
communication between the healthcare team and patient, making patients collaborative participants in their own care.

\section{ACKNOWLEDGEMENTS}

We thank the participants of the study.

The study group includes the following diabetology experts: Alberto Giacinto Ambrogio, Milan; Cristiana Baggiore, Florence; Laura Bartone, Reggio Calabria; Marzia Bongiovanni, Rome; Francesca Borroni, Civitanova Marche (Macerata); Lucia Brodosi, Bologna; Maria Turchese Caletti, Ravenna; Sergio Cappello, Molfetta (Bari); Diego Carleo, Naples; Francesco Carlino, Maddaloni (Caserta); Alessandro Cavarape, Udine; Silvestre Cervone, San Marco in Lamis (Foggia); Isabella Colletti, Portogruaro (Venice); Federica D'Angelo, San Benedetto del Tronto (Ascoli Piceno); Pasquale De Cata, Pavia; Giuseppe Della Tepa, Naples; Paolo Falasca, Rome; Vera Frison, Cittadella (Padua); Alessandra Fusco, Naples; Lorenza Gagliardi, Forlì (Forlì-Cesena); Marco Giordano, Palermo ; Chiara Gottardi, Trieste; Lucia Gottardo, Venice; Elena Gramaglia, Turin; Giovanna Gregori, Carrara (Massa e Carrara); Vito Antonio Ladiana, Massafra (Taranto); Carlo Lalli, Perugia; Antonio Lanzilli, Naples; Maurizio Latini, Rome; Patrizia Li Volsi, Pordenone; Filomena Lo Conte, Palo del Colle (Bari); Valeria Maggi, Bari; Sabina Marchetto, Treviso; Stefano Masi, Baiano (Avellino); Paola Massucco, Turin; Giuseppe Memoli, Ariano Irpino (Avellino); Viviana Minarelli, Perugia; Francesco Mollo, Rovigo; Chiara Moretti, Rome; Giovanni Nasini, Perugia; Elena Nazzari, Savona; Isabella Negro, Saonara (Padua); Vincenzo Nuzzo, Naples; Francesca Paggi, Ancona; Simone Pampanelli, Perugia; Paola Pantanetti, Fermo; Bernadetta Pasquino, Merate (Lecco); Massimiliano Petrelli, Ancona; Maria Rosa Pizzo, Sapri (Salerno); Federica Portolan, Cles (Trento); Maria Chiara Quinto, Bari; Andrea Renzullo, Nola (Naples); Giovanni Ridola, Palermo; Vittoria Romanazzi, Bari; Giovanna Saraceno, Turin; Maurizio Sudano, Urbino (Pesaro e Urbino); Linda Tartaglione, Rome; Camilla Tinari, Milan; Valentina
Tommasi, Rome; Eva Zanchetta, San Donà di Piave (Venice); Milena Zanon, San Stino di Livenza (Venice); Luca Zenoni, Seriate (Bergamo).

Funding. The journal's Rapid Service Fee was funded by Ethos s.r.l. through a Novo Nordisk S.p.A. unconditional grant. Novo Nordisk S.p.A. did not influence and was not involved in data collection, interpretation, and analysis. No funding or sponsorship was received for this study.

Editorial Assistance. Editorial assistance was provided by Alessandro Lico of Ethos s.r.l., through a Novo Nordisk S.p.A. unconditional grant, for technical support during the manuscript submission process.

Authorship. All named authors meet the International Committee of Medical Journal Editors (ICMJE) criteria for authorship for this article, take responsibility for the integrity of the work as a whole, and have given their approval for this version to be published.

Authors' Contributions. All the authors (Gaetano Leto, Ilaria Barchetta, Lorenzo De Candia, Maria Grazia Magotti, Marco Cianciullo, Roberta Manti, Carlo Negri, Vincenzo Cimino, Alessandro R. Dodesini, Francesco Zerella, Roberto Baratta) contributed to study design, data interpretation, drafting and review of the manuscript.

Disclosures. None of the authors (Gaetano Leto, Ilaria Barchetta, Lorenzo De Candia, Maria Grazia Magotti, Marco Cianciullo, Roberta Manti, Carlo Negri, Vincenzo Cimino, Alessandro R. Dodesini, Francesco Zerella, Roberto Baratta) have anying to disclose.

Compliance with Ethics Guidelines. The study is based on a survey that does not contain any studies involving the participation of human subjects or patient data management and does not aim to modify the current clinical practice of participants. Consequently, according to current legislation (Legislative Decree 211/2003, a transposition of Directive 2001/20/ 
EU), this study did not require ethical approval. All experts involved in the survey were informed of the study's objectives and the possibility of publishing the results in a peer-reviewed article. The participation was voluntary. They expressed their consent to participate in the survey after logging into the secure online survey platform via credentials by actively clicking on the appropriate box.

Data Availability. All data generated or analyzed during this study are included in this published article.

Open Access. This article is licensed under a Creative Commons Attribution-NonCommercial 4.0 International License, which permits any non-commercial use, sharing, adaptation, distribution and reproduction in any medium or format, as long as you give appropriate credit to the original author(s) and the source, provide a link to the Creative Commons licence, and indicate if changes were made. The images or other third party material in this article are included in the article's Creative Commons licence, unless indicated otherwise in a credit line to the material. If material is not included in the article's Creative Commons licence and your intended use is not permitted by statutory regulation or exceeds the permitted use, you will need to obtain permission directly from the copyright holder. To view a copy of this licence, visit http://creativecommons.org/licenses/by$\mathrm{nc} / 4.0 /$.

\section{REFERENCES}

1. Saeedi P, Petersohn I, Salpea P, Malanda B, Karuranga $S$, Unwin $N$, Colagiuri $S$, Guariguata L, Motala AA, Ogurtsova K, Shaw JE, Bright D, Williams R, IDF Diabetes Atlas Committee. Global and regional diabetes prevalence estimates for 2019 and projections for 2030 and 2045: Results from the International Diabetes Federation Diabetes Atlas, 9th edition. Diabetes Res Clin Pract. 2019;157:107843. https://doi.org/10.1016/j.diabres.2019.107843.

2. Russel Jones D, Pouwer F, Khunti K. Identification of barriers to insulin therapy and approaches to overcoming them. Diabetes Obes Metab.
2018;20(3):488-96. https://doi.org/10.1111/dom. 13132.

3. Fadini GP, Disoteo O, Candido R, Di Bartolo P, Laviola L, Consoli A. Delphi-based consensus on treatment intensification in type 2 diabetes subjects failing basal insulin supported oral treatment: focus on basal insulin + GLP-1 receptor agonist combination therapies. Diabetes Ther. 2021;12(3): 781-800. https://doi.org/10.1007/s13300-02101012-2.

4. Garner S, Littlejohns P. Disinvestment from low value clinical interventions: NICEly done? BMJ. 2011;27(343): d4519. https://doi.org/10.1136/bmj. d4519.

5. Morgan DJ, Brownlee $\mathrm{S}$, Leppin $\mathrm{AL}$, Kressin $\mathrm{N}$, Dhruva SS, Levin L, Landon BE, Zezza MA, Schmidt H, Saini V, Elshaug AG. Setting a research agenda for medical overuse. BMJ. 2015;25(351): h4534. https://doi.org/10.1136/bmj.h4534.

6. Davies MJ, D'Alessio DA, Fradkin J, Kernan WN, Mathieu C, Mingrone G, Rossing P, Tsapas A, Wexler DJ, Buse JB. Management of hyperglycemia in type 2 diabetes, 2018. A consensus report by the American Diabetes Association (ADA) and the European Association for the Study of Diabetes (EASD). Diabetes Care. 2018;41(12):2669-701. https://doi.org/10.2337/dci18-0033.

7. Buse JB, Wexler DJ, Tsapas A, Rossing P, Mingrone G, Mathieu C, D'Alessio DA, Davies MJ. 2019 Update to: management of hyperglycemia in type 2 diabetes, 2018. A consensus report by the American Diabetes Association (ADA) and the European Association for the Study of Diabetes (EASD). Diabetes Care. 2020;43(2):487-93. https://doi.org/10. 2337/dci19-0066 (Epub 2019 Dec 19. Erratum in: Diabetes Care. 2020 Jul;43(7):1670).

8. Cosentino F, Grant PJ, Aboyans V, Bailey CJ, Ceriello A, Delgado V, Federici M, Filippatos G, Grobbee DE, Hansen TB, Huikuri HV, Johansson I, Jüni P, Lettino M, Marx N, Mellbin LG, Östgren CJ, Rocca B, Roffi M, Sattar N, Seferović PM, Sousa-Uva M, Valensi P, Wheeler DC, ESC Scientific Document Group. 2019 ESC Guidelines on diabetes, pre-diabetes, and cardiovascular diseases developed in collaboration with the EASD. Eur Heart J. 2020;41(2):255-323. https://doi.org/10.1093/ eurheartj/ehz486 (Erratum in: Eur Heart J. 2020 Dec 1;41(45):4317).

9. Cassel CK, Guest JA. Choosing wisely: helping physicians and patients make smart decisions about their care. JAMA. 2012;307(17):1801-2. https://doi. org/10.1001/jama.2012.476.

10. Pintaudi B, Scatena A, Piscitelli G, Frison V, Corrao S, Manicardi V, Graziano G, Rossi MC, Gallo M, 
Mannino D, Di Bartolo P, Nicolucci A. Clinical profiles and quality of care of subjects with type 2 diabetes according to their cardiovascular risk: an observational, retrospective study. Cardiovasc Diabetol. 2021;20(1):59. https://doi.org/10.1186/ s12933-021-01251-4.

11. Fadini GP, Bottigliengo D, D'Angelo F, Cavalot F, Bossi AC, Zatti G, Baldi I, Avogaro A, DARWIN-T2D Network. Comparative effectiveness of DPP-4 inhibitors versus sulfonylurea for the treatment of type 2 diabetes in routine clinical practice: a retrospective multicenter real-world study. Diabetes Ther. 2018;9(4):1477-90. s13300-018-0452-y.

12. Heyward J, Christopher J, Sarkar S, Shin JI, Kalyani RR, Alexander GC. Ambulatory noninsulin treatment of type 2 diabetes mellitus in the United States, 2015-2019. Diabetes Obes Metab. 2021. https://doi.org/10.1111/dom.14408.

13. Mannucci E, Monami M, Candido R, Pintaudi B, Targher G, SID-AMD joint panel for Italian Guidelines on Treatment of Type 2 Diabetes. Effect of insulin secretagogues on major cardiovascular events and all-cause mortality: a meta-analysis of randomized controlled trials. Nutr Metab Cardiovasc Dis. 2020;30(10):1601-8. https://doi.org/10. 1016/j.numecd.2020.05.032.

14. Consoli A, Czupryniak L, Duarte R, Jermendy G, Kautzky-Willer A, Mathieu C, Melo M, Mosenzon O, Nobels F, Papanas N, Roman G, Schnell O, Sotiropoulos A, Stehouwer CDA, Tack CJ, Woo V, Fadini GP, Raz I. Positioning sulphonylureas in a modern treatment algorithm for patients with type 2 diabetes: expert opinion from a European consensus panel. Diabetes Obes Metab. 2020;22(10): 1705-13. https://doi.org/10.1111/dom.14102.

15. UK Hypoglycaemia Study Group. Risk of hypoglycaemia in types 1 and 2 diabetes: effects of treatment modalities and their duration. Diabetologia. 2007;50(6):1140-7. s00125-007-0599-y. https://doi.org/10.1007/

16. Silbert R, Salcido-Montenegro A, Rodriguez-Gutierrez R, Katabi A, McCoy RG. Hypoglycemia among patients with type 2 diabetes: epidemiology, risk factors, and prevention strategies. Curr Diabetes Rep. 2018;18(8):53. https://doi.org/10.1007/ s11892-018-1018-0.

17. Östenson CG, Geelhoed-Duijvestijn P, Lahtela J, Weitgasser R, Markert Jensen M, Pedersen-Bjergaard U. Self-reported non-severe hypoglycaemic events in Europe. Diabetes Med. 2014;31(1):92-101. https://doi.org/10.1111/dme.12261.

18. Martín-Timón I, Del Cañizo-Gómez FJ. Mechanisms of hypoglycemia unawareness and implications in diabetic patients. World J Diabetes. 2015;6(7): 912-26. https://doi.org/10.4239/wjd.v6.i7.912.

19. Schopman JE, Geddes J, Frier BM. Prevalence of impaired awareness of hypoglycaemia and frequency of hypoglycaemia in insulin-treated type 2 diabetes. Diabetes Res Clin Pract. 2010;87(1):64-8. https://doi.org/10.1016/j.diabres.2009.10.013.

20. Cranston I, Lomas J, Maran A, Macdonald I, Amiel SA. Restoration of hypoglycaemia awareness in patients with long-duration insulin-dependent diabetes. Lancet. 1994;344(8918):283-7. https:// doi.org/10.1016/s0140-6736(94)91336-6.

21. Saragoni S, Perrone V, Buda S, Genovese S, Laurenzi A, Mannucci E, Degli EL. Analysis of clinical outcome and healthcare resource use in insulin treated diabetic patients based on self-monitoring of blood glucose levels. Int $\mathrm{J}$ Diabetol Vasc Dis Res. 2017;5(2):183-8.

22. Gehlaut RR, Dogbey GY, Schwartz FL, Marling CR, Shubrook JH. Hypoglycemia in type 2 diabetesmore common than you think: a continuous glucose monitoring study. J Diabetes Sci Technol. 2015;9(5):999-1005. https://doi.org/10.1177/ 1932296815581052

23. American Diabetes Association. 9 Cardiovascular disease and risk management: standards of medical care in diabetes-2018. Diabetes Care. 2018;41(Suppl 1):S86-104. https://doi.org/10.2337/dc18-S009.

24. Heerspink HJL, Stefánsson BV, Correa-Rotter R, Chertow GM, Greene T, Hou FF, Mann JFE, McMurray JJV, Lindberg M, Rossing P, Sjöström CD, Toto RD, Langkilde AM, Wheeler DC, DAPA-CKD Trial Committees and Investigators. Dapagliflozin in patients with chronic kidney disease. N Engl J Med. 2020;383(15):1436-46. https://doi.org/10. 1056/NEJMoa2024816.

25. McCoy RG, Dykhoff HJ, Sangaralingham L, Ross JS, Karaca-Mandic P, Montori VM, Shah ND. Adoption of new glucose-lowering medications in the USthe case of SGLT2 inhibitors: nationwide cohort study. Diabetes Technol Ther. 2019;21(12):702-12. https://doi.org/10.1089/dia.2019.0213.

26. Khunti K, Millar-Jones D. Clinical inertia to insulin initiation and intensification in the UK: a focused literature review. Prim Care Diabetes. 2017;11(1): 3-12. https://doi.org/10.1016/j.pcd.2016.09.003.

27. American Diabetes Association. 9 Pharmacologic approaches to glycemic treatment: standards of medical care in diabetes-2019. Diabetes Care. 2019;42(Suppl 1):S90-102. https://doi.org/10.2337/ dc19-S009. 
28. Desai U, Kirson NY, Kim J, Khunti K, King S, Trieschman E, Hellstern M, Hunt PR, Mukherjee J. Time to treatment intensification after monotherapy failure and its association with subsequent glycemic control among 93,515 patients with type 2 diabetes. Diabetes Care. 2018;41(10):2096-104. https://doi.org/10.2337/dc17-0662.

29. Paul SK, Klein K, Thorsted BL, Wolden ML, Khunti K. Delay in treatment intensification increases the risks of cardiovascular events in patients with type 2 diabetes. Cardiovasc Diabetol. 2015;7(14):100. https://doi.org/10.1186/s12933-015-0260-x.PMID: 26249018;PMCID:PMC4528846.

30. Khunti K, Nikolajsen A, Thorsted BL, Andersen M, Davies MJ, Paul SK. Clinical inertia with regard to intensifying therapy in people with type 2 diabetes treated with basal insulin. Diabetes Obes Metab. 2016;18(4):401-9. https://doi.org/10.1111/dom. 12626.

31. Khunti S, Khunti K, Seidu S. Therapeutic inertia in type 2 diabetes: prevalence, causes, consequences and methods to overcome inertia. Ther Adv Endocrinol Metab. 2019;3(10):2042018819844694. https://doi.org/10.1177/2042018819844694.

32. Andreozzi F, Candido R, Corrao S, Fornengo R, Giancaterini A, Ponzani P, Ponziani MC, Tuccinardi F, Mannino D. Clinical inertia is the enemy of therapeutic success in the management of diabetes and its complications: a narrative literature review. Diabetol Metab Syndr. 2020;17(12):52. https://doi. org/10.1186/s13098-020-00559-7.

33. Marso SP, Daniels GH, Brown-Frandsen K, Kristensen P, Mann JF, Nauck MA, Nissen SE, Pocock S, Poulter NR, Ravn LS, Steinberg WM, Stockner M, Zinman B, Bergenstal RM, Buse JB, LEADER Steering Committee; LEADER Trial Investigators. Liraglutide and cardiovascular outcomes in type 2 diabetes. N Engl J Med. 2016;375(4):311-22. https://doi.org/ 10.1056/NEJMoa1603827.

34. Pfeffer MA, Claggett B, Diaz R, Dickstein K, Gerstein HC, Køber LV, Lawson FC, Ping L, Wei X, Lewis EF, Maggioni AP, McMurray JJ, Probstfield JL, Riddle MC, Solomon SD, Tardif JC, ELIXA Investigators. Lixisenatide in patients with type 2 diabetes and acute coronary syndrome. N Engl J Med. 2015;373(23):2247-57. https://doi.org/10.1056/ NEJMoa1509225.

35. Marso SP, McGuire DK, Zinman B, Poulter NR, Emerson SS, Pieber TR, Pratley RE, Haahr PM, Lange M, Brown-Frandsen K, Moses A, Skibsted S, Kvist K, Buse JB, DEVOTE Study Group. Efficacy and safety of degludec versus glargine in type 2 diabetes. N Engl J Med. 2017;377(8):723-32. https://doi.org/ 10.1056/NEJMoa1615692.
36. Gough SC, Bode B, Woo V, et al. Efficacy and safety of a fixed-ratio combination of insulin degludec and liraglutide (IDegLira) compared with its components given alone: results of a phase 3, open-label, randomised, 26-week, treat-to-target trial in insulin-naive patients with type 2 diabetes. Lancet Diabetes Endocrinol. 2014;2:885-93. https://doi. org/10.1016/S2213-8587(14)70174-3.

37. Rosenstock J, Aronson R, Grunberger G, et al. Benefits of LixiLan, a titratable fixed-ratio combination of insulin glargine plus lixisenatide, versus insulin glargine and lixisenatide monocomponents in type 2 diabetes inadequately controlled on oral agents: the LixiLan-O randomized trial. Diabetes Care. 2016;39:2026-35. https://doi.org/10.2337/dc160917.

38. Associazione Medici Diabetologi (AMD). Avvio della terapia insulinica dal 2005 al 2011: Approcci prescrittivi e outcome dell'assistenza. (In Italian) https://aemmedi.it/files/ANNALI-AMD/2014/2014_ Mono_terapia-insulinica_2005-2011.pdf. Accessed 29 Apr 2021.

39. Cheng AYY, Wong J, Freemantle N, Acharya SH, Ekinci E. The Safety and efficacy of second-generation basal insulin analogues in adults with type 2 diabetes at risk of hypoglycemia and use in other special populations: a narrative review. Diabetes Ther. 2020;11(11):2555-93. https://doi.org/10. 1007/s13300-020-00925-8.

40. Wysham C, Bhargava A, Chaykin L, de la Rosa R, Handelsman Y, Troelsen LN, Kvist K, Norwood P. Effect of insulin degludec vs insulin glargine U100 on hypoglycemia in patients with type 2 diabetes: the SWITCH 2 randomized clinical trial. JAMA. 2017;318(1):45-56. https://doi.org/10.1001/jama. 2017.7117.

41. Yale JF, Aroda VR, Charbonnel B, Sinclair AJ, Trescoli C, Cahn A, Bigot G, Merino-Trigo A, BrulleWohlhueter C, Bolli GB, Ritzel R. Glycaemic control and hypoglycaemia risk with insulin glargine 300 $\mathrm{U} / \mathrm{mL}$ versus glargine $100 \mathrm{U} / \mathrm{mL}$ : a patient-level meta-analysis examining older and younger adults with type 2 diabetes. Diabetes Metab. 2020;46(2): 110-8. https://doi.org/10.1016/j.diabet.2018.10. 002.

42. Knudsen ST, Lapolla A, Schultes B, Tentolouris N, Catarig AM, Wolden ML, Siegmund T. Clinical benefits of switching to insulin degludec irrespective of previous basal insulin therapy in people with type 1 or type 2 diabetes: evidence from a European, multicentre, retrospective, non-interventional study (EU-TREAT). Diabet Med. 2019;36(7):868-77. https://doi.org/10.1111/dme.13976.

43. Bron $M$, Marynchenko M, Yang $H, Y u$ AP, Wu EQ. Hypoglycemia, treatment discontinuation, and 
costs in patients with type 2 diabetes mellitus on oral antidiabetic drugs. Postgrad Med. 2012;124(1): 124-32. https://doi.org/10.3810/pgm.2012.01. 2525 .

44. Heller SR, Peyrot M, Oates SK, Taylor AD. Hypoglycemia in patient with type 2 diabetes treated with insulin: it can happen. BMJ Open Diabetes Res Care. 2020;8(1): e001194. https://doi.org/10.1136/ bmjdrc-2020-001194.

45. Kloos C, Burghardt K, Müller UA, Kramer G, Müller N, Wolf G, Kuniss N. Reduction of severe hypoglycaemia in people with type 2 diabetes after a structured inpatient intervention. Exp Clin Endocrinol Diabetes. 2019. https://doi.org/10.1055/a0983-1559.

46. Polonsky WH, Henry RR. Poor medication adherence in type 2 diabetes: recognizing the scope of the problem and its key contributors. Patient Prefer Adherence. 2016;22(10):1299-307. https://doi.org/ 10.2147/PPA.S106821.

47. Mann DM, Ponieman D, Leventhal H, Halm EA. Predictors of adherence to diabetes medications: the role of disease and medication beliefs. J Behav Med. 2009;32(3):278-84. https://doi.org/10.1007/ s10865-009-9202-y.

48. Polonsky WH, Skinner TC. Perceived treatment efficacy: an overlooked opportunity in diabetes care. Clin Diabetes. 2010;28(2):89-92. https://doi. org/10.2337/diaclin.28.2.89.

49. Polonsky WH, Arsenault J, Fisher L, Kushner P, Miller EM, Pearson TL, Tracz M, Harris S, Hermanns N, Scholz BM, Pollom RK, Perez-Nieves M, Pollom RD, Hadjiyianni I. Initiating insulin: how to help people with type 2 diabetes start and continue insulin successfully. Int J Clin Pract. 2017;71(8): e12973. https://doi.org/10.1111/ijcp.12973.

50. Berard L, Bonnemaire M, Mical M, Edelman S. Insights into optimal basal insulin titration in type 2 diabetes: results of a quantitative survey. Diabetes Obes Metab. 2018;20(2):301-8. https://doi.org/10. 1111/dom.13064.

51. de Vries ST, Keers JC, Visser R, de Zeeuw D, HaaijerRuskamp FM, Voorham J, Denig P. Medication beliefs, treatment complexity, and non-adherence to different drug classes in patients with type 2 diabetes. J Psychosom Res. 2014;76(2):134-8. https://doi.org/10.1016/j.jpsychores.2013.11.003.

52. Choudhry NK, Fischer MA, Avorn J, Liberman JN, Schneeweiss S, Pakes J, Brennan TA, Shrank WH.
The implications of therapeutic complexity on adherence to cardiovascular medications. Arch Intern Med. 2011;171(9):814-22. https://doi.org/ 10.1001/archinternmed.2010.495.

53. Elnaem MH, Irwan NA, Abubakar U, Syed Sulaiman SA, Elrggal ME, Cheema E. Impact of medication regimen simplification on medication adherence and clinical outcomes in patients with long-term medical conditions. Patient Prefer Adherence. 2020;2(14):2135-45. https://doi.org/10.2147/PPA. S268499.

54. Ho PM, Rumsfeld JS, Masoudi FA, McClure DL, Plomondon ME, Steiner JF, Magid DJ. Effect of medication nonadherence on hospitalization and mortality among patients with diabetes mellitus. Arch Intern Med. 2006;166(17):1836-41. https:// doi.org/10.1001/archinte.166.17.1836.

55. Walker RJ, Strom Williams J, Egede LE. Influence of race, ethnicity and social determinants of health on diabetes outcomes. Am J Med Sci. 2016;351(4): 366-73. https://doi.org/10.1016/j.amjms.2016.01. 008.

56. Street RL Jr, Makoul G, Arora NK, Epstein RM. How does communication heal? Pathways linking clinician-patient communication to health outcomes. Patient Educ Couns. 2009;74(3):295-301. https:// doi.org/10.1016/j.pec.2008.11.015.

57. Hirsch LJ, Strauss KW. The injection technique factor: what you don't know or teach can make a difference. Clin Diabetes. 2019;37(3):227-33. https://doi.org/10.2337/cd18-0076.

58. Gentile S, Guarino G, Della Corte T, Marino G, Fusco A, Corigliano G, Colarusso S, Piscopo M, Improta MR, Corigliano M, Martedi E, Oliva D, Russo V, Simonetti R, Satta E, Romano C, Vaia S, Strollo F. Lipohypertrophy in elderly insulin-treated patients with type 2 diabetes. Diabetes Ther. 2021;12(1):107-19. https://doi.org/10.1007/ s13300-020-00954-3.

59. Blanco M, Hernández MT, Strauss KW, Amaya M. Prevalence and risk factors of lipohypertrophy in insulin-injecting patients with diabetes. Diabetes Metab. 2013;39(5):445-53. https://doi.org/10.1016/ j.diabet.2013.05.006.

60. Holstein A, Stege H, Kovacs P. Lipoatrophy associated with the use of insulin analogues: a new case associated with the use of insulin glargine and review of the literature. Expert Opin Drug Saf. 2010;9(2):225-31. https://doi.org/10.1517/ 14740330903496402. 